\title{
Interdialytic Weight Gain and Cardiovascular Outcome in Incident Hemodialysis Patients
}

\author{
Mi Jung Lee ${ }^{a} \quad$ Fa Mee Doh ${ }^{a} \quad$ Chan Ho Kim ${ }^{a}$ Hyang Mo Koo ${ }^{a}$ Hyung Jung Oha \\ Jung Tak Park ${ }^{a}$ Seung Hyeok Han ${ }^{a}$ Tae-Hyun Yoo ${ }^{a, b}$ Yong-Lim Kim ${ }^{\text {e,f }}$ \\ Yon Su Kim ${ }^{c, f}$ Chul Woo Yang d,f Nam-Ho Kimf,g Shin-Wook Kanga, b, f \\ ${ }^{a}$ Department of Internal Medicine, Yonsei University College of Medicine, ${ }^{b}$ Severance Biomedical Science Institute, \\ Brain Korea 21 PLUS, Yonsei University, ' Department of Internal Medicine, Seoul National University College of \\ Medicine, d Department of Internal Medicine, Catholic University of Korea College of Medicine, Seoul, \\ e Department of Internal Medicine, Kyungpook National University School of Medicine, ${ }^{f}$ Clinical Research Center \\ for End-Stage Renal Disease, Daegu, and ${ }^{9}$ Department of Internal Medicine, Chonnam National University Medical \\ School, Gwangju, Korea
}

\section{Key Words}

Cardiovascular outcome $\cdot$ Hemodialysis $\cdot$ Interdialytic weight gain

\begin{abstract}
Background: Interdialytic weight gain (IDWG) has been regarded as a surrogate of volume overload, but also as a marker of a better nutritional status in end-stage renal disease (ESRD) patients on hemodialysis (HD). This paradoxical meaning of IDWG requires further investigation, particularly in adverse cardiovascular outcomes. Methods: A prospective cohort of 1,013 incident HD patients from 36 HD centers of the Clinical Research Center for ESRD in Korea was included. Patients were categorized into five groups according to the IDWG\%, a ratio of absolute IDWG to dry weight: $<1.0$, $\geq 4.0$, and every 1.0 increment in between. Primary outcome was major adverse cardiac and cerebrovascular events (MACCE). Results: During a mean follow-up of 18.7 months, primary outcome was observed in 104 patients (10.3\%). In multivariate analysis, compared to patients with IDWG\% of
\end{abstract}

1.0-1.9 (reference group), the hazard ratios (HRs) for primary outcome in the IDWG\% <1.0, 2.0-2.9, 3.0-3.9, and $\geq 4.0$ groups were 1.10 [95\% confidence interval (CI) 0.55-2.20, $\mathrm{p}=0.80], 1.15$ (95\% Cl 0.59-2.27, p = 0.68), 1.80 (95\% Cl 0.95$3.41, p=0.07)$, and $1.93(95 \% \mathrm{Cl} 1.02-3.64, \mathrm{p}=0.04)$, respectively. Furthermore, even when residual renal function and 24-hour urine volume were adjusted, IDWG\% $\geq 4.0$ remained as a significant predictor of primary outcome (HR 2.03, 95\% $\mathrm{Cl} 1.02-4.02, \mathrm{p}=0.04)$. Conclusion: Increased IDWG\% is a significant independent predictor of MACCE in incident HD patients. It could be helpful to prevent excessive IDWG for improving clinical outcomes in incident HD patients.

(c) 2014 S. Karger AG, Base

\section{Introduction}

Interdialytic weight gain (IDWG), which corresponds to ultrafiltration losses during hemodialysis (HD), is the result of salt and water ingestion minus urine output between two consecutive dialysis sessions $[1,2]$. Previous

\section{KARGER}

E-Mail karger@karger.com www.karger.com/ajn
(C) 2014 S. Karger AG, Basel

0250-8095/14/0395-0427\$39.50/0
Shin-Wook Kang, MD, PhD

Department of Internal Medicine, College of Medicine

Severance Biomedical Science Institute, Brain Korea 21 PLUS, Yonsei University

134 Shinchon-Dong, Seodaemun-Gu, Seoul 120-752 (Korea)

E-Mail kswkidney@yuhs.ac 
studies have revealed that excessive IDWG is associated with adverse clinical outcomes [2-6], finding it to be an independent predictor of all-cause and cardiovascular mortality in patients undergoing long-term HD [2]. In addition, accumulating evidence shows that IDWG is significantly associated with increases in blood pressure (BP) and left ventricular hypertrophy (LVH), both of which can increase the risk of cardiovascular mortality in patients with end-stage renal disease (ESRD) [1, 7-12]. Moreover, IDWG was also considered one of several indicators of non-adherence to dialysis therapy, a significant predictor of mortality and hospitalization in prevalent HD patients $[3,4]$. However, the impact of IDWG on clinical outcomes is not straightforward [13-20]. IDWG is proportional to the amount of food intake, as well as fluid and salt. In this regard, several studies have found a significant positive correlation between IDWG and nutritional markers, such as normalized protein catabolic rate (nPCR), serum albumin and creatinine, and body mass index (BMI) [13-19]. Therefore, in some ways, IDWG is regarded as a marker of a better nutritional status, which is a favorable prognostic factor in ESRD patients [16-19].

These conflicting results have led us to further verify the relationship between IDWG and clinical outcomes in patients starting HD. To date, most previous studies investigating the impact of IDWG on mortality and morbidity were conducted in Western prevalent HD patients $[2,3,5,6]$, only Japanese prevalent HD patients were studied as a part of the Dialysis Outcomes and Practice Patterns Study (DOPPS) [4]. Considering differences in culinary culture, nutritional status, and dialysis practice pattern, it has clinical relevance to investigate the prognostic impact of IDWG in Asian incident HD patients. Furthermore, prior studies did not include residual renal function (RRF), 24-hour urine volume, and inflammatory biomarkers in the final analysis, which are significantly associated with IDWG and survival of HD patients $[2,3,5,6,18]$. Therefore, in the present study, we clarified the prognostic value of IDWG in Korean incident HD patients from the Clinical Research Center for ESRD (CRC for ESRD) cohort, a nationwide prospective observational multicenter cohort in consideration of RRF, 24hour urine volume, and inflammation.

\section{Subjects and Methods}

Study Design and Subjects

All ESRD patients who started HD between August 1, 2008 and December 31, 2012 in 36 centers of the CRC for ESRD in Korea were initially screened for this study. This study is a nationwide multi- center joint network prospective cohort of ESRD patients in Korea designed to improve survival rates and quality of life and to create effective treatment guidelines (clinicaltrial.gov NCT00931970). Patients who were younger than 18 years, had histories of peritoneal dialysis or kidney transplantation before $\mathrm{HD}$, had underlying active malignancy, or were expected to survive less than 3 months were excluded before the initial screening. Among 1,245 incident HD patients, those who died within 3 months of the commencement of $\mathrm{HD}$, who did not receive three times weekly HD, or who had insufficient baseline demographic, laboratory, or IDWG data were also excluded from the study. Finally, a total of 1,013 incident HD patients were included in the final analysis.

This study was carried out in accordance with the Declaration of Helsinki. The study protocol was approved by the institutional review board at each participating center, and all patients provided their written informed consent to participate in the study.

\section{Data Collection}

Demographic and clinical data were collected at the time of study entry, and included age, gender, primary renal disease, comorbidities, type of vascular access, and medications. Coronary artery disease was defined as a history of angioplasty, coronary artery bypass grafts, myocardial infarction, or angina and cerebrovascular accident from a history of transient ischemic attack, stroke, or carotid endarterectomy; peripheral artery disease was defined as a history of claudication, ischemic limb loss and/or ulceration, or any peripheral revascularization procedure. Predialysis systolic and diastolic BP was recorded. BMI was calculated and subjective global assessment (SGA) was scored to access nutritional status. Single pooled fractional urea clearance (Kt/V) urea and sodium concentrations of dialysate were obtained on the day of the midweek dialysis session, 3 months after HD initiation. RRF and urine volume were determined by a 24 -hour urine collection. The following laboratory data were measured from predialysis fasting blood samples taken on the day of the midweek dialysis session close to the time of discharge, when the patients were considered to be clinically stable and in a euvolemic state, and every 3 months thereafter: hemoglobin, white blood cell, blood urea nitrogen (BUN), creatinine, calcium, phosphorus, intact parathyroid hormone, glucose, uric acid, albumin, total cholesterol, low-density lipoprotein cholesterol, high-density lipoprotein cholesterol, ferritin, and plasma sodium concentrations. High-sensitivity C-reactive protein (hs-CRP) levels were measured by a latex-enhanced immunonephelometric method using a BNII analyzer (Dade Behring, Newark, Del., USA). Echocardiography was performed on a non-dialysis day close to the time of discharge, based on the imaging protocol recommended by the American Society of Echocardiography. Multiple reproducibility, inter-reader reliability, intrareader reliability, and reader drift analyses were performed at a core echocardiography laboratory (Kyungpook National University, Daegu, Korea) on a random sample of $3 \%$ of the entire cohort each year.

\section{Assessment of IDWG}

Absolute IDWG was defined as the difference between predialysis body weight of the midweek dialysis session and preceding postdialysis body weight, and the ratio of absolute IDWG to patient's dry weight was defined as IDWG\%. Dry weight was determined by the patients' physicians (nephrologists) in the context of symptoms of intradialytic hypotension, BP, edema, or pulmonary 
edema on chest X-ray. To mitigate intrapersonal variability, the mean value of three IDWG\%2-4 months after HD initiation was used in the analysis.

\section{Outcome Measures}

All deaths and hospitalization events were retrieved from the database of the CRC for ESRD and were carefully reviewed. Primary outcome was the incidence of major adverse cardiac and cerebrovascular events (MACCE), defined as death or hospitalization from myocardial infarction, unstable angina, new onset or worsening of congestive heart failure, stroke, or arterial revascularization.

\section{Statistical Analysis}

Statistical analysis was performed using SPSS for Windows version 18.0 (SPSS, Inc., Chicago, Ill., USA). Continuous variables were expressed as mean $\pm \mathrm{SD}$, or median (interquartile range), and categorical variables as a number (percentage). Normality of distribution was ascertained by the Kolmogorov-Smirnov test. Subjects were categorized into five groups according to IDWG\%: $<1.0$, $\geq 4.0$, and every 1.0 increment in between. To compare demographics, clinical characteristics, and laboratory findings among the groups, ANOVA with Bonferroni post hoc test or KruskalWallis test was used for continuous variables and the $\chi^{2}$ test for categorical variables. Uni- and multivariate linear regression analyses were performed to identify independent determinants of IDWG\%. The independent prognostic value of IDWG\% for primary outcome was ascertained by Cox proportional hazards regression analysis, which included significant variables from the univariate analysis and variables associated with nutrition and inflammation in ESRD (BMI, SGA, and serum ferritin and hs-CRP concentrations). Since data of echocardiography and 24-hour urine study were available in 676 and 811 patients, respectively, additional models of linear regression analysis and Cox analysis were conducted for these patients. $\mathrm{p}$ values $<0.05$ were considered statistically significant.

\section{Results}

\section{Baseline Characteristics according to IDWG\% Categories}

The baseline demographics, clinical characteristics, and laboratory findings 3 months after HD commencement according to IDWG\% categories are shown in tables 1 and 2 . The mean age was $58.3 \pm 14.2(21-80)$ years, and 609 patients $(60.1 \%)$ were male. Diabetic nephropathy (53.8\%) was the most common cause of ESRD, followed by hypertension (14.4\%). At the initiation of HD, 138 (13.6\%) and 116 patients (11.4\%) had coronary artery disease and congestive heart failure, respectively. The mean IDWG\% of all patients was $2.8 \pm 1.9 \%$, and the mean IDWG\% for each group was $0.4,1.5,2.5,3.5$, and $5.5 \%$, respectively. There was a significant increased trend in the proportion of patients with diabetes, predialysis systolic $\mathrm{BP}$ at 3 months after HD initiation; serum glucose

IDWG and Cardiovascular Outcome in HD and phosphorus concentrations also increased with IDWG\%, while residual urine volume, hemoglobin, serum albumin and calcium, and plasma sodium levels tended to be significantly lower as IDWG\% increased. There were no significant differences in comorbid diseases, RRF, type of vascular access, dialysis adequacy, the use of medications, and echocardiographic parameters such as left atrial diameter (LAD), LV mass index (LVMI), and LV ejection fraction (LVEF).

\section{Association of IDWG\% with Clinical and Biochemical Parameters}

To identify independent variables associated with IDWG\%, multivariate linear regression analysis was performed (table 3). Male gender, diabetes mellitus, predialysis systolic BP, and serum phosphorus concentrations were positively correlated with IDWG\%, while there were significant inverse relationships of IDWG\% with BMI, serum albumin and calcium, and plasma sodium levels. When RRF and 24-hour urine volumes were included in the regression model (model 2), 24-hour urine volume $(\beta=-0.14, p=0.001)$ was revealed to be an independent predictor of IDWG\%. Moreover, the associations of IDWG\% with diabetes mellitus, predialysis systolic BP, $\mathrm{BMI}$, serum albumin, and plasma sodium concentrations remained consistent.

\section{IDWG\% as an Independent Risk Factor for MACCE}

During a mean follow-up duration of $18.7 \pm 11.7$ months, 32 patients $(3.2 \%)$ died from cardiovascular causes, and primary outcome was observed in 104 patients (10.3\%). The most often MACCE was myocardial infarction (27 patients, $2.7 \%$ ), followed by unstable and stable angina pectoris (16 patients, $1.6 \%$, respectively) (www.karger.com/doi/10.1159/000362743 for online suppl. table 1). Cardiovascular death rates and the incidence rates of primary outcome were the highest in patients with IDWG\% $\geq 4.0$ (2.88 and 9.77 per 100 patient-years, respectively). Univariate Cox proportional hazards analysis revealed that age [hazard ratio (HR) $1.02,95 \%$ confidence interval (CI) $1.01-1.04, \mathrm{p}=0.002$ ], the presence of diabetes (HR 1.625, 95\% CI 1.08-2.46, $\mathrm{p}=0.02)$ and previous cardiovascular disease (HR 2.50, 95\% CI 1.70-3.68, p < 0.001), log hs-CRP (HR 1.30, 95\% CI $1.07-1.59, \mathrm{p}=0.01$ ), and serum albumin levels (HR $0.71,95 \%$ CI $0.51-0.98, \mathrm{p}=0.04$ ) were associated with an increased risk of primary outcome. In multivariate analysis, compared to patients with IDWG\% of 1.0-1.9 (reference group), the HRs of the IDWG\% $<1.0,2.0-2.9,3.0-$ 3.9 , and $\geq 4.0$ groups were 1.10 (95\% CI $0.55-2.20, \mathrm{p}=$ 
Table 1. Baseline demographics, clinical characteristics of subjects according to IDWG\% categories

\begin{tabular}{|c|c|c|c|c|c|c|c|}
\hline & $\begin{array}{l}\text { All } \\
(n=1,013)\end{array}$ & $\begin{array}{l}<1.0 \% \\
(\mathrm{n}=182)\end{array}$ & $\begin{array}{l}1.0-1.9 \% \\
(n=202)\end{array}$ & $\begin{array}{l}2.0-2.9 \% \\
(n=223)\end{array}$ & $\begin{array}{l}3.0-3.9 \% \\
(n=172)\end{array}$ & $\begin{array}{l}\geq 4.0 \% \\
(n=234)\end{array}$ & $\mathrm{p}$ \\
\hline IDWG, $\%$ of dry weight & $2.8 \pm 1.9$ & $0.4 \pm 0.3$ & $1.5 \pm 0.3$ & $2.5 \pm 0.3$ & $3.5 \pm 0.3$ & $5.5 \pm 1.4$ & \\
\hline Age, years & $58.3 \pm 14.2$ & $58.6 \pm 15.3$ & $58.8 \pm 14.3$ & $57.9 \pm 14.6$ & $57.7 \pm 13.0$ & $58.4 \pm 13.6$ & 0.9 \\
\hline Male, n (\%) & $609(60.1)$ & $127(69.8)$ & $121(59.9)$ & $128(57.4)$ & $100(58.1)$ & $133(56.8)$ & 0.06 \\
\hline \multicolumn{7}{|l|}{ Primary renal disease, $\mathrm{n}(\%)$} & 0.02 \\
\hline Diabetic nephropathy & $545(53.8)$ & $74(40.6)$ & $104(51.5)$ & $115(51.6)$ & $97(56.4)$ & $155(66.2)$ & \\
\hline Glomerulonephritis & $129(12.7)$ & $29(15.9)$ & $27(13.4)$ & $29(13.0)$ & $22(12.8)$ & $22(9.4)$ & \\
\hline Polycystic kidney disease & $30(3.0)$ & $11(6.0)$ & $9(4.5)$ & $4(1.8)$ & $2(1.2)$ & $4(1.7)$ & \\
\hline Other $^{\mathrm{a}}$ & $76(7.5)$ & $15(8.2)$ & $14(6.9)$ & $16(7.2)$ & $14(8.1)$ & $17(7.3)$ & \\
\hline Unknown & $87(8.6)$ & $21(11.5)$ & $17(8.5)$ & $20(9.0)$ & $13(7.6)$ & $16(6.8)$ & \\
\hline Modified CCI & $5.3 \pm 2.5$ & $5.1 \pm 2.7$ & $5.3 \pm 2.4$ & $5.1 \pm 2.3$ & $5.2 \pm 2.2$ & $5.6 \pm 2.6$ & 0.29 \\
\hline \multicolumn{8}{|l|}{ Comorbid disease, $\mathrm{n}(\%)$} \\
\hline CVA & $109(10.8)$ & $18(9.9)$ & $25(12.4)$ & $25(11.2)$ & $15(8.7)$ & $26(11.1)$ & 0.78 \\
\hline $\mathrm{CHF}$ & $116(11.4)$ & $15(8.2)$ & $24(11.9)$ & $31(13.9)$ & $16(9.3)$ & $30(12.8)$ & 0.22 \\
\hline $\mathrm{CVD}^{\mathrm{b}}$ & $322(31.8)$ & $55(30.2)$ & $65(32.1)$ & $73(32.7)$ & $49(28.5)$ & $80(34.2)$ & 0.76 \\
\hline Smoker, n (\%) & $438(43.3)$ & $88(48.3)$ & $82(40.6)$ & $89(39.9)$ & $77(44.8)$ & $102(43.6)$ & 0.09 \\
\hline Predialysis weight, kg & $62.4 \pm 11.0$ & $63.2 \pm 11.3$ & $63.1 \pm 11.6$ & $62.1 \pm 11.0$ & $63.3 \pm 10.3$ & $61.0 \pm 10.6$ & 0.15 \\
\hline Postdialysis weight, $\mathrm{kg}$ & $61.1 \pm 10.8$ & $63.1 \pm 11.1$ & $62.2 \pm 11.1$ & $60.8 \pm 10.7$ & $61.5 \pm 10.1$ & $58.6 \pm 10.3$ & 0.001 \\
\hline Predialysis SBP, mm Hg & $144.2 \pm 23.3$ & $141.9 \pm 24.5$ & $144.8 \pm 24.5$ & $143.9 \pm 21.4$ & $145.3 \pm 23.4$ & $144.9 \pm 23.1$ & 0.63 \\
\hline Predialysis DBP, mm Hg & $76.1 \pm 14.5$ & $76.0 \pm 13.9$ & $75.5 \pm 14.6$ & $76.2 \pm 13.4$ & $76.3 \pm 15.0$ & $76.6 \pm 15.5$ & 0.9 \\
\hline \multicolumn{7}{|l|}{ Vascular access, $\mathrm{n}(\%)$} & 0.31 \\
\hline AVF or AVG & $295(29.1)$ & $47(25.8)$ & $66(32.7)$ & $76(34.0)$ & $48(28.0)$ & $58(24.8)$ & \\
\hline Temporary catheter & $682(67.3)$ & $125(68.7)$ & $126(62.3)$ & $142(63.8)$ & $120(69.7)$ & $169(72.2)$ & \\
\hline Unknown & $36(3.6)$ & $10(5.5)$ & $10(5.0)$ & $5(2.2)$ & $4(2.3)$ & $7(3.0)$ & \\
\hline \multicolumn{8}{|l|}{ Echocardiographic parameters ${ }^{c}$} \\
\hline $\mathrm{LAD}, \mathrm{cm}$ & $4.2 \pm 0.7$ & $4.1 \pm 0.7$ & $4.3 \pm 0.7$ & $4.3 \pm 0.8$ & $4.3 \pm 0.6$ & $4.3 \pm 0.7$ & 0.31 \\
\hline LVMI, g/m² & $194.1 \pm 82.3$ & $191.6 \pm 67.6$ & $200.1 \pm 78.6$ & $195.8 \pm 67.3$ & $199.1 \pm 82.3$ & $202.7 \pm 78.2$ & 0.15 \\
\hline LVEF, \% & $58.6 \pm 10.5$ & $59.8 \pm 10.4$ & $59.3 \pm 10.1$ & $59.5 \pm 10.1$ & $58.3 \pm 10.4$ & $58.5 \pm 11.4$ & 0.36 \\
\hline \multicolumn{3}{|c|}{$\begin{array}{l}\text { Data are expressed as the mean } \pm \mathrm{SD} \text { or number of patients }(\%) \text {. } \\
\mathrm{CAD}=\text { Coronary artery disease } \mathrm{PAD}=\text { peripheral artery disease; } \\
\mathrm{CVA}=\text { cerebrovascular accidents; } \mathrm{CHF}=\text { congestive heart failure; } \\
\mathrm{CVD}=\text { cardiovascular disease } \mathrm{CCI}=\mathrm{Charlson} \text { comorbidity index; } \\
\mathrm{SBP}=\text { systolic blood pressure; } \mathrm{DBP}=\text { diastolic blood pressure; }\end{array}$} & \multicolumn{5}{|c|}{$\begin{array}{l}\text { AVF = arteriovenous fistula; AVG = arteriovenous graft; RAS = } \\
\text { renin-angiotensin system. } \\
{ }^{\mathrm{a}} \text { Interstitial nephritis, obstructive uropathy, and post status of } \\
\text { nephrectomy. }{ }^{\mathrm{b}} \mathrm{A} \text { composite of CAD, PAD, CVA, and CHF } \\
{ }^{c} \text { Echocardiographic parameters were available in } 676 \text { patients. }\end{array}$} \\
\hline
\end{tabular}


Table 2. Clinical and laboratory parameters 3 months after HD commencement according to IDWG\% categories

\begin{tabular}{|c|c|c|c|c|c|c|c|}
\hline & $\begin{array}{l}\text { All } \\
(\mathrm{n}=1,013)\end{array}$ & $\begin{array}{l}<1.0 \% \\
(\mathrm{n}=182)\end{array}$ & $\begin{array}{l}1.0-1.9 \% \\
(\mathrm{n}=202)\end{array}$ & $\begin{array}{l}2.0-2.9 \% \\
(\mathrm{n}=223)\end{array}$ & $\begin{array}{l}3.0-3.9 \% \\
(\mathrm{n}=172)\end{array}$ & $\begin{array}{l}\geq 4.0 \% \\
(\mathrm{n}=234)\end{array}$ & $\mathrm{p}$ \\
\hline Predialysis weight, $\mathrm{kg}$ & $62.1 \pm 11.0$ & $61.8 \pm 10.4$ & $62.4 \pm 11.5$ & $61.7 \pm 11.2$ & $63.2 \pm 10.9$ & $61.5 \pm 11.0$ & 0.67 \\
\hline Predialysis SBP, $\mathrm{mm} \mathrm{Hg}$ & $144.2 \pm 21.7$ & $136.4 \pm 19.7$ & $143.4 \pm 22.8$ & $144.4 \pm 21.3$ & $145.3 \pm 22.2$ & $147.8 \pm 21.0$ & 0.001 \\
\hline Predialysis DBP, mm Hg & $77.1 \pm 13.1$ & $74.7 \pm 13.0$ & $77.8 \pm 12.6$ & $77.0 \pm 12.5$ & $76.8 \pm 13.4$ & $78.6 \pm 13.6$ & 0.22 \\
\hline BMI & $23.1 \pm 3.4$ & $23.3 \pm 3.2$ & $23.4 \pm 3.7$ & $23.2 \pm 3.5$ & $23.3 \pm 3.4$ & $22.7 \pm 3.3$ & 0.16 \\
\hline Dialysate $\mathrm{Na}, \mathrm{mEq} / \mathrm{l}$ & $139.1 \pm 1.9$ & $139.0 \pm 2.3$ & $139.1 \pm 1.6$ & $139.1 \pm 1.9$ & $139.2 \pm 1.7$ & $139.1 \pm 1.8$ & 0.9 \\
\hline $\mathrm{RRF}, \mathrm{ml} / \mathrm{min} / 1.73 \mathrm{~m}^{2}$ & $7.9 \pm 4.2$ & $8.4 \pm 4.8$ & $7.8 \pm 3.9$ & $7.7 \pm 4.6$ & $7.4 \pm 3.6$ & $7.9 \pm 3.9$ & 0.14 \\
\hline Urine volume, $1 /$ day & $0.98 \pm 0.55$ & $1.14 \pm 0.56$ & $1.05 \pm 0.54$ & $0.95 \pm 0.57$ & $0.88 \pm 0.47$ & $0.91 \pm 0.58$ & $<0.001$ \\
\hline Hemoglobin, g/dl & $10.8 \pm 1.5$ & $11.0 \pm 1.4$ & $11.0 \pm 1.3$ & $10.7 \pm 1.2$ & $10.8 \pm 1.3$ & $10.6 \pm 1.2$ & 0.01 \\
\hline White blood cells, $\times 10^{3} / \mu \mathrm{l}$ & $7.2 \pm 3.1$ & $7.0 \pm 2.9$ & $7.1 \pm 2.9$ & $7.0 \pm 3.3$ & $7.2 \pm 2.7$ & $7.5 \pm 3.3$ & 0.33 \\
\hline Blood urea nitrogen, $\mathrm{mg} / \mathrm{dl}$ & $53.1 \pm 21.5$ & $51.9 \pm 21.7$ & $51.9 \pm 18.5$ & $53.5 \pm 23.1$ & $54.6 \pm 22.3$ & $54.5 \pm 20.9$ & 0.05 \\
\hline Creatinine, $\mathrm{mg} / \mathrm{dl}$ & $7.6 \pm 3.0$ & $7.4 \pm 2.8$ & $7.5 \pm 2.9$ & $7.5 \pm 2.4$ & $7.9 \pm 3.7$ & $7.8 \pm 2.8$ & 0.07 \\
\hline LDL cholesterol, mg/dl & $83.3 \pm 28.8$ & $87.6 \pm 28.3$ & $85.3 \pm 28.9$ & $84.7 \pm 30.2$ & $81.4 \pm 27.0$ & $78.4 \pm 29.4$ & 0.11 \\
\hline HDL cholesterol, $\mathrm{mg} / \mathrm{dl}$ & $43.8 \pm 15.2$ & $43.5 \pm 14.9$ & $44.4 \pm 15.9$ & $44.1 \pm 14.6$ & $43.1 \pm 14.6$ & $43.9 \pm 16.1$ & 0.9 \\
\hline Calcium, mg/dl & $7.8 \pm 1.1$ & $7.8 \pm 1.2$ & $7.9 \pm 0.9$ & $7.7 \pm 1.1$ & $7.6 \pm 1.0$ & $7.6 \pm 1.0$ & $<0.001$ \\
\hline Phosphorus, mg/dl & $5.4 \pm 1.9$ & $5.2 \pm 1.9$ & $5.2 \pm 1.8$ & $5.3 \pm 1.7$ & $5.8 \pm 2.1$ & $5.6 \pm 2.0$ & 0.009 \\
\hline iPTH, pg/ml & $197(109-324)$ & $191(104-317)$ & $195(106-316)$ & $220(119-369)$ & $196(127-320)$ & $188(99-299)$ & 0.35 \\
\hline Ferritin, ng/ml & $180(127-356)$ & $239(138-390)$ & $180(105-279)$ & $206(113-366)$ & $193(119-394)$ & $227(129-391)$ & 0.05 \\
\hline hs-CRP, mg/l & $1.38(1.21-1.57)$ & $1.37(1.01-1.74)$ & $1.31(0.91-1.72)$ & $1.76(1.29-2.22)$ & $1.04(0.69-1.39)$ & $1.45(1.03-1.87)$ & 0.17 \\
\hline $\mathrm{Na}, \mathrm{mEq} / \mathrm{l}$ & $137.0 \pm 5.0$ & $138.3 \pm 4.1$ & $137.3 \pm 5.0$ & $137.3 \pm 4.3$ & $136.5 \pm 5.3$ & $136.1 \pm 5.6$ & 0.001 \\
\hline
\end{tabular}

Data are expressed as mean \pm SD or median (interquartile range). $\mathrm{SBP}=$ Systolic blood pressure; $\mathrm{DBP}=$ diastolic blood pressure; $\mathrm{Na}=$ sodium; $\mathrm{LDL}=$ low-density lipoprotein; HDL = high-density lipoprotein; $\mathrm{PTH}=$ intact parathyroid hormone.

Table 3. Uni- and multivariate linear regression analysis of clinical and biochemical variables for increased IDWG\%

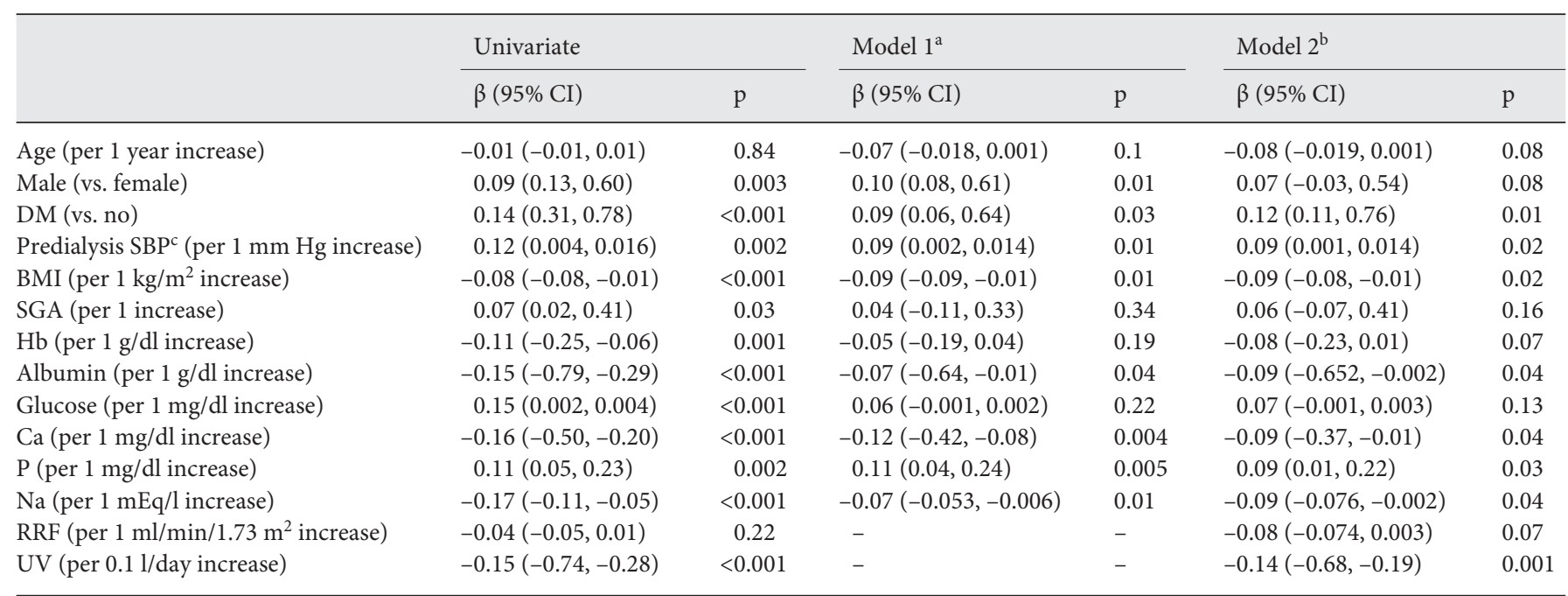

$\mathrm{DM}=$ Diabetes mellitus; $\mathrm{SBP}=$ systolic blood pressure $\mathrm{Hb}=$ hemoglobin $\mathrm{Ca}=$ calcium; $\mathrm{P}=$ phosphorus; $\mathrm{Na}=$ sodium; $\mathrm{UV}=$ urine volume.

a Adjusted for sex, age, DM, predialysis SBP, BMI, SGA, Hb, albumin, glucose, Ca, P, and Na. ${ }^{b}$ Model $1+$ GFR and 24 -hour UV. ${ }^{c}$ Predialysis SBP was recorded 3 months after HD initiation. 
Table 4. Cox proportional hazard models of IDWG\% categories for MACCE

\begin{tabular}{|c|c|c|c|c|c|c|}
\hline & \multicolumn{2}{|l|}{ Unadjusted } & \multicolumn{2}{|l|}{ Model $1^{\mathrm{a}}$} & \multicolumn{2}{|l|}{ Model $2^{b}$} \\
\hline & HR (95\% CI) & $\mathrm{p}$ & HR (95\% CI) & $\mathrm{p}$ & HR (95\% CI) & $\mathrm{p}$ \\
\hline$<1.0$ & $1.07(0.54-2.11)$ & 0.85 & $1.71(0.80-2.46)$ & 0.23 & $1.10(0.55-2.20)$ & 0.80 \\
\hline $1.0-1.9$ & 1 (reference) & & 1 (reference) & & 1 (reference) & \\
\hline $2.0-2.9$ & $1.17(0.57-2.29)$ & 0.65 & $1.13(0.65-1.96)$ & 0.66 & $1.15(0.59-2.27)$ & 0.68 \\
\hline $3.0-3.9$ & $1.63(0.87-3.05)$ & 0.13 & $1.73(1.00-2.98)$ & 0.05 & $1.80(0.95-3.41)$ & 0.07 \\
\hline$\geq 4.0$ & $2.07(1.12-3.82)$ & 0.02 & $1.74(1.04-2.91)$ & 0.04 & $1.93(1.02-3.64)$ & 0.04 \\
\hline
\end{tabular}

$\mathrm{DM}=$ Diabetes mellitus; $\mathrm{SBP}=$ systolic blood pressure; $\mathrm{Ca}=$ calcium; $\mathrm{P}=$ phosphorus; $\mathrm{Na}=$ sodium.

a Adjusted for sex, age, DM, previous history of cardiovascular disease, predialysis SBP 3 months after HD initiation. ${ }^{\mathrm{b}}$ Model $1+\mathrm{BMI}, \mathrm{SGA}$, and biochemical data (albumin, $\mathrm{Ca}, \mathrm{P}, \log$ ferritin, log hs-CRP, and plasma $\mathrm{Na}$ ).

$0.80), 1.15$ (95\% CI $0.59-2.27, \mathrm{p}=0.68), 1.80$ (95\% CI $0.95-3.41, \mathrm{p}=0.07$ ), and 1.93 (95\% CI 1.02-3.64, $\mathrm{p}=$ $0.04)$, respectively, after adjustment for demographic characteristics, nutritional status, and inflammatory biochemical parameters (table 4, model 2). Furthermore, the predictive value of IDWG $\% \geq 4.0$ for primary outcome remained significant after adjusting for each baseline echocardiographic parameter [model 2 (table 4) + LAD, HR 1.91, 95\% CI 1.03-3.53, $\mathrm{p}=0.04$; model $2+$ LVMI, HR 1.89, 95\% CI 1.02-3.50, $\mathrm{p}=0.04$; model $2+\mathrm{LVEF}, \mathrm{HR}$ $1.88,95 \%$ CI 1.01-3.47, $\mathrm{p}=0.04)$ ].

\section{Prognostic Value of IDWG\% in Subgroup Stratified by}

Residual Urine Volume

IDWG\% $\geq 4.0$ was an independent predictor of MAC$\mathrm{CE}$ even after adjustment for RRF and 24-hour urine volumes [model 2 (table 4) + RRF and 24-hour urine volume, HR 2.03, 95\% CI 1.02-4.02, p = 0.04]. In addition, when the patients were dichotomized by the median value of 24 hour urine volume $(0.9 \mathrm{l} /$ day $)$, the prognostic value of IDWG $\% \geq 4.0$ for primary outcome was significant in the smaller urine output group (HR 1.95, 95\% CI 1.01-3.02, $\mathrm{p}=0.04$ ) after adjustment for various confounding factors, including nutritional and inflammatory biomarkers. The risk of IDWG $\% \geq 4.0$ for primary outcome was also higher in the larger urine output group, but did not reach statistical significance (HR 1.32, 95\% CI 0.57-3.04, $\mathrm{p}=0.12$ ).

\section{Discussion}

IDWG has been considered a surrogate of volume overload in ESRD patients undergoing HD [1-7, 12], but it is also regarded as a marker of a better nutritional status
[13-19]. Even though a number of previous studies have investigated the prognostic value of IDWG in prevalent HD patients, the results have been inconsistent $[2-6,16-$ 20]. In the current study, we demonstrate for the first time that excessive IDWG ( $\geq 4.0 \%$ of dry weight) is a significant independent predictor of MACCE in incident ESRD patients starting $\mathrm{HD}$, even after adjustment for the presence of diabetes and previous cardiovascular disease, malnutrition, inflammation, RRF, and 24-hour urine volume. Moreover, this study shows that IDWG has significant inverse correlations with nutritional markers, but positive correlations with predialysis systolic BP. These findings suggest that prevention of excessive IDWG may be beneficial to clinical outcomes, even in incident HD patients, partly via protecting the heart from the deleterious effect of hypertension.

IDWG is a weight gain between two consecutive dialysis sessions, which is primarily dependent on the patient's fluid and sodium intake $[1,2]$. To date, mounting evidence indicates that a greater IDWG is associated with poor survival in ESRD patients on HD [2-6]. In Swedish HD patients, the extent of IDWG was significantly greater in patients with cardiovascular outcomes compared to those without [5]. Patients with IDWG $\geq 5.7 \%$ of dry weight, one of the criteria used to define non-compliance, were also found to have a higher mortality risk [3, 4]. Moreover, a large cohort study by Kalantar-Zadeh et al. [2] revealed that the risks of all-cause and cardiovascular mortality were significantly higher in long-term HD patients with IDWG $\geq 4.0 \mathrm{~kg}$. Furthermore, a very recent study demonstrated that IDWG $>3.0 \mathrm{~kg}$ was associated with a 1.29-fold increase in all-cause mortality, independent of dialysis session length [6]. However, most previous studies, which investigated the adverse effects of 
IDWG on the clinical outcomes in ESRD patients on HD, were conducted in prevalent HD patients $[2,3,5,6]$, and presented limited data on Asian population [4]. The differences in culinary culture, body size, comorbid disease, dialysis environment, and clinical course of Asian dialysis patients warrant a study specifically investigating the prognostic impact of IDWG in Asian incident HD patients. In the present study, we demonstrate that excessive IDWG ( $\geq 4.0 \%$ of dry weight) is a significant predictor of poor cardiovascular outcome in a nationally representative cohort of Korean incident HD patients, an outcome consistent with the aforementioned studies [2-6].

Meanwhile, some previous studies have indicated that a higher IDWG represents a better nutritional status, which led to favorable outcomes in ESRD patients [1619]. IDWG had direct correlations with nPCR, serum albumin, creatinine, and BUN concentrations, as well as BMI [13-19]. Lopez-Gomez et al. [18] found that the 5 -year mortality risk was significantly higher in patients with IDWG\% of $<3$ compared to those with IDWG\% $\geq 3$. Patients with higher IDWG\% also had significantly higher nPCR, serum albumin, prealbumin, and phosphorus levels, all of which were closely correlated with amount of protein intake. They suggested that larger amounts of food and beverage intake resulted in a greater IDWG, and that the close association between IDWG and nutrition outweighed the negative effects of IDWG on fluid overload. However, other studies failed to demonstrate a significant relationship between IDWG and serum albumin levels, which is the most commonly used indicator of nutritional status [21-23]. Chen et al. [21] showed that new HD patients with higher IDWG had significantly lower BMI during the first year of therapy and that there was no significant difference in nutritional markers such as serum albumin, phosphorus, creatinine, and BUN concentrations among patients with different IDWG\%. The results of our study also did not find any significant positive correlations between nutritional parameters and IDWG\%, which was in agreement with the results of the study by Chen et al. [21]. The conflicting results regarding the association of IDWG\% and nutritional status in HD patients may be partly attributed to different study populations (prevalent vs. incident). Compared to prevalent HD patients, RRF and urine volume are relatively preserved in incident ESRD patients starting HD, and urine volume is certainly one of the principal determinants of IDWG in HD patients. The current study also revealed that 24-hour urine volume was the largest in patients with IDWG\% $<1.0$ in spite of comparable RRF, and that residual urine volume was a significant independent predictor of

IDWG and Cardiovascular Outcome in HD
IDWG\%. In addition, when RRF and urine volume were included in multivariate analysis, the HR of excessive IDWG was further increased. Taken together, even though the precise measurement of food, salt, and water intake was not performed, we inferred that the patients with lower IDWG were those who had ability to compensate fluid overload by larger residual urine volume rather than who had lesser appetite or poor oral intake. On the other hand, the impact of IDWG on the clinical outcome was further elucidated according to the amount of residual urine volume. The prognostic value of IDWG $\% \geq 4.0$ for primary outcome was significant in the smaller urine output group after adjustment for various confounding factors, including nutritional and inflammatory biomarkers. Based on these results, we surmised that excessive IDWG had a deleterious effect on the clinical outcome, especially in incident HD patients with small residual urine volume.

The mechanism by which IDWG affects cardiovascular morbidity and mortality can be speculated from the cardiovascular burden of volume overload, volume fluctuation, and arterial hypertension. Since most HD patients are treated with dialysis on a three times weekly schedule, intermittent ultrafiltration can lead to fluctuation in body fluid. These daily fluctuations in extracellular fluid volume might promote cardiac remodeling by the activation of mammalian target of rapamycin (mTOR) pathway [24-29], sympathetic nervous system, and renin-angiotensin-aldosterone pathway [30,31], resulting in $\mathrm{LVH}$ and cardiac fibrosis [6]. In the present study, the baseline echocardiographic parameters were similar among the five IDWG\% groups, and the independent prognostic value of IDWG $\% \geq 4$.0 remained significant even after adjusting for each baseline echocardiographic parameter. Nevertheless, since echocardiography was performed once at the time of HD initiation, it was impossible to demonstrate the changes in echocardiographic parameters, which might imply the detrimental effect of volume fluctuation on cardiac remodeling, due to lack of follow-up echocardiography. A future study with short-term follow-up echocardiography is necessary to clarify whether volume fluctuation during the first 4 months of HD treatment can worsen cardiac dysfunction in incident HD patients. Meanwhile, this study found that there was a significant increased trend in predialysis systolic BP 3 months after HD commencement as IDWG\% increased. Since hypertension is closely associated with LVH in ESRD patients [26, 27], we inferred that hypertension in patients with greater IDWG\% might aggravate $\mathrm{LVH}$, eventually leading to poor cardiovascular out-

Am J Nephrol 2014;39:427-435

DOI: $10.1159 / 000362743$ 
comes. Moreover, in a study of $125 \mathrm{HD}$ patients, 24-hour ambulatory BP monitoring revealed that greater IDWG was associated with a linear increase in the slope of $\mathrm{BP}$ during interdialytic period and the circadian amplitude was blunted by increments in IDWG [12]. Increased nocturnal BP and loss of normal circadian rhythm were known to be implicated in cardiovascular mortality in HD patients $[32,33]$. Based on these findings, arterial hypertension might also contribute to poor clinical outcomes in this study.

Our study has several limitations. First, IDWG was not determined at every dialysis session. Furthermore, dry weight is variable during the early period after the initiation of HD treatment [34]. Therefore, the mean values of at least three IDWG\% after 2-4 months of HD initiation were used in the current study. Nevertheless, it was difficult to examine whether the change in IDWG\% during the study period exerted any influence on clinical outcomes. Second, an objective assessment of dry weight by bioimpedence analyses, relative plasma volume monitoring, or chest ultrasonography was not performed in this study, making it difficult to discriminate whether our subjects were in a volume-overloaded or depleted state at the end of the HD session. Third, since the study subjects were all Korean incident HD patients, the association between IDWG and the clinical outcome mortality may not be generalized to other populations. Fourth, the followup duration was relatively short, making it difficult to recruit a sufficient number of patients for a longitudinal study. Since this prospective observation cohort study is ongoing, the long-term association between IDWG\% and cardiovascular events can be further elucidated in the future. Lastly, primary outcome in the present study was relatively small compared to those in previous studies on Western ESRD patients. We hypothesize that the difference is mainly attributed to disparate ethnicities, since the mortality rates of our patients were comparable to those of Japanese patients on HD [35]. Despite these limitations, the current study investigated the association of IDWG with various nutritional and inflammatory parameters, and RRF. In addition, the independent prognostic impact of IDWG on cardiovascular outcomes was revealed in a large and ethnically homogenous incident HD patient cohort.

In conclusion, the results of our study demonstrate that excessive IDWG ( $\geq 4.0 \%$ of dry weight) is a significant independent predictor of MACCE in incident HD patients. Furthermore, there was a significant correlation between IDWG and predialysis systolic BP. These findings suggest that prevention of excessive IDWG may be beneficial to cardiovascular outcomes even in incident HD patients, partly via protecting the heart from the deleterious effect of hypertension.

\section{Acknowledgments}

This work was supported by the Brain Korea 21 PLUS Project for Medical Science, Yonsei University College of Medicine, and the National Research Foundation of Korea (NRF) grant funded by the Korea government (MSIP) (No. NRF-2011-0030086).

\section{Disclosure Statement}

The authors have no conflicts of interest to disclose.

\section{References}

1 Inrig JK, Patel UD, Gillespie BS, Hasselblad V, Himmelfarb J, Reddan D, Lindsay RM, Winchester JF, Stivelman J, Toto R, Szczech LA: Relationship between interdialytic weight gain and blood pressure among prevalent hemodialysis patients. Am J Kidney Dis 2007;50: 108-118.e101-e104.

2 Kalantar-Zadeh K, Regidor DL, Kovesdy CP, Van Wyck D, Bunnapradist S, Horwich TB, Fonarow GC: Fluid retention is associated with cardiovascular mortality in patients undergoing long-term hemodialysis. Circulation 2009;119:671-679.

-3 Leggat JE Jr, Orzol SM, Hulbert-Shearon TE, Golper TA, Jones CA, Held PJ, Port FK: Noncompliance in hemodialysis: predictors and survival analysis. Am J Kidney Dis 1998;32: 139-145.
4 Saran R, Bragg-Gresham JL, Rayner HC, Goodkin DA, Keen ML, Van Dijk PC, Kurokawa K, Piera L, Saito A, Fukuhara S, Young EW, Held PJ, Port FK: Nonadherence in hemodialysis: associations with mortality, hospitalization, and practice patterns in the DOPPS. Kidney Int 2003;64:254-262.

5 Holmberg B, Stegmayr BG: Cardiovascular conditions in hemodialysis patients may be worsened by extensive interdialytic weight gain. Hemodial Int 2009;13:27-31.

-6 Flythe JE, Curhan GC, Brunelli SM: Disentangling the ultrafiltration rate-mortality association: the respective roles of session length and weight gain. Clin J Am Soc Nephrol 2013; 8:1151-1161

\footnotetext{
7 Koc Y, Unsal A, Kayabasi H, Oztekin E, Sakaci T, Ahbap E, Yilmaz M, Akgun AO: Impact of volume status on blood pressure and left ventricle structure in patients undergoing chronic hemodialysis. Ren Fail 2011;33:377381.

8 Zoccali C, Benedetto FA, Mallamaci F, Tripepi G, Giacone G, Stancanelli B, Cataliotti A, Malatino LS: Left ventricular mass monitoring in the follow-up of dialysis patients: prognostic value of left ventricular hypertrophy progression. Kidney Int 2004;65:14921498.

$\checkmark 9$ Kim SJ, Oh HJ, Yoo DE, Shin DH, Lee MJ, Kim HR, Park JT, Han SH, Yoo TH, Choi KH, Kang SW: Electrocardiographic left ventricular hypertrophy and outcome in hemodialysis patients. PLoS One 2012;7:e35534.
} 
10 Konings CJ, Kooman JP, Schonck M, Dammers R, Cheriex E, Palmans Meulemans AP, Hoeks AP, van Kreel B, Gladziwa U, van der Sande FM, Leunissen KM: Fluid status, blood pressure, and cardiovascular abnormalities in patients on peritoneal dialysis. Perit Dial Int 2002;22:477-487.

- 11 Leypoldt JK, Cheung AK, Delmez JA, Gassman JJ, Levin NW, Lewis JA, Lewis JL, Rocco MV: Relationship between volume status and blood pressure during chronic hemodialysis. Kidney Int 2002;61:266-275.

12 Agarwal R, Light RP: Arterial stiffness and interdialytic weight gain influence ambulatory blood pressure patterns in hemodialysis patients. Am J Physiol Renal Physiol 2008; 294:F303-F308.

13 Sherman RA, Cody RP, Rogers ME, Solanchick JC: Interdialytic weight gain and nutritional parameters in chronic hemodialysis patients. Am J Kidney Dis 1995;25:579-583.

- 14 Teraoka S, Toma H, Nihei H, Ota K, Babazono T, Ishikawa I, Shinoda A, Maeda K, Koshikawa S, Takahashi T, et al: Current status of renal replacement therapy in Japan. Am J Kidney Dis 1995;25:151-164.

15 Testa A, Beaud JM: The other side of the coin: interdialytic weight gain as an index of good nutrition. Am J Kidney Dis 1998;31:830-834.

- 16 Kimmel PL, Varela MP, Peterson RA, Weihs KL, Simmens SJ, Alleyne S, Amarashinge A, Mishkin GJ, Cruz I, Veis JH: Interdialytic weight gain and survival in hemodialysis patients: effects of duration of ESRD and diabetes mellitus. Kidney Int 2000;57:1141-1151.

-17 Szczech LA, Reddan DN, Klassen PS, Coladonato J, Chua B, Lowrie EG, Lazarus JM, Owen WF Jr: Interactions between dialysisrelated volume exposures, nutritional surrogates and mortality among ESRD patients. Nephrol Dial Transplant 2003;18:1585-1591.

18 Lopez-Gomez JM, Villaverde M, Jofre R, Rodriguez-Benitez P, Perez-Garcia R: Interdialytic weight gain as a marker of blood pressure, nutrition, and survival in hemodialysis patients. Kidney Int Suppl 2005;93:S63-S68.
19 Sarkar SR, Kotanko P, Levin NW: Interdialytic weight gain: implications in hemodialysis patients. Semin Dial 2006;19:429-433.

20 Hecking M, Karaboyas A, Saran R, Sen A, Inaba M, Rayner H, Horl WH, Pisoni RL, Robinson BM, Sunder-Plassmann G, Port FK: Dialysate sodium concentration and the association with interdialytic weight gain, hospitalization, and mortality. Clin J Am Soc Nephrol 2012;7:92-100.

21 Chen YW, Chen HH, Pan CF, Chang CY, Wu CJ: Interdialytic weight gain does not influence the nutrition of new hemodialysis patients. J Ren Nutr 2012;22:41-49.

22 Ifudu O, Uribarri J, Rajwani I, Vlacich V, Reydel K, Delosreyes G, Friedman EA: Relation between interdialytic weight gain, body weight and nutrition in hemodialysis patients. Am J Nephrol 2002;22:363-368.

23 Kayikcioglu M, Tumuklu M, Ozkahya M, Ozdogan O, Asci G, Duman S, Toz H, Can LH, Basci A, Ok E: The benefit of salt restriction in the treatment of end-stage renal disease by haemodialysis. Nephrol Dial Transplant 2009;24:956-962.

24 Chazot C, Wabel P, Chamney P, Moissl U, Wieskotten S, Wizemann V: Importance of normohydration for the long-term survival of haemodialysis patients. Nephrol Dial Transplant 2012;27:2404-2410.

25 Cheng LT, Tian JP, Tang LJ, Chen HM, Gu Y, Du FH, Wang T: Why is there significant overlap in volume status between hypertensive and normotensive patients on dialysis? Am J Nephrol 2008;28:508-516.

26 Gunal AI, Karaca I, Aygen B, Yavuzkir M, Dogukan A, Celiker H: Strict fluid volume control and left ventricular hypertrophy in hypertensive patients on chronic haemodialysis: a cross-sectional study. J Int Med Res 2004;32:70-77.
27 Ozkahya M, Toz H, Qzerkan F, Duman S, Ok E, Basci A, Mees EJ: Impact of volume control on left ventricular hypertrophy in dialysis patients. J Nephrol 2002;15:655-660.

28 Wizemann V, Wabel P, Chamney P, Zaluska W, Moissl U, Rode C, Malecka-Masalska T, Marcelli D: The mortality risk of overhydration in haemodialysis patients. Nephrol Dial Transplant 2009;24:1574-1579.

29 McMullen JR, Sherwood MC, Tarnavski O, Zhang L, Dorfman AL, Shioi T, Izumo S: Inhibition of mTOR signaling with rapamycin regresses established cardiac hypertrophy induced by pressure overload. Circulation 2004; 109:3050-3055.

30 Cotter G, Felker GM, Adams KF, Milo-Cotter O, O'Connor CM: The pathophysiology of acute heart failure - is it all about fluid accumulation? Am Heart J 2008;155:9-18.

31 Van Wamel AJ, Ruwhof C, van der Valk-Kokshoom LE, Schrier PI, van der Laarse A: The role of angiotensin II, endothelin- 1 and transforming growth factor- $\beta$ as autocrine/paracrine mediators of stretch-induced cardiomyocyte hypertrophy. Mol Cell Biochem 2001;218:113-124.

32 Amar J, Vernier I, Rossignol E, Bongard V, Arnaud C, Conte JJ, Salvador M, Chamontin B: Nocturnal blood pressure and 24-hour pulse pressure are potent indicators of mortality in hemodialysis patients. Kidney Int 2000;57:2485-2491.

33 Tripepi G, Fagugli RM, Dattolo P, Parlongo G, Mallamaci F, Buoncristiani U, Zoccali C: Prognostic value of 24-hour ambulatory blood pressure monitoring and of night/day ratio in nondiabetic, cardiovascular eventsfree hemodialysis patients. Kidney Int 2005; 68:1294-1302.

34 Chazot C, Charra B, Vo Van C, Jean G, Vanel T, Calemard E, Terrat JC, Ruffet M, Laurent G: The Janus-faced aspect of 'dry weight'. Nephrol Dial Transplant 1999;14:121-124.

- 35 Robinson BM, Port FK: International hemodialysis patient outcomes comparisons revisited: the role of practice patterns and other factors. Clin J Am Soc Nephrol 2009;4(suppl 1):S12-S17. 